\title{
Knowledge of Workers about their Occupational Hazards at Sugarcane Factory in Luxor Governorate
}

\author{
Mariam F. Maky ${ }^{1}$, Asmaa K. Hassan ${ }^{2} \&$ Safaa R. Osman ${ }^{3}$. \\ 1. Demonstrator at Family \& Community Health Nursing Department, Faculty of Nursing - South Valley University, \\ Egypt. \\ 2. Assistant Professor of Family \&Community Health Nursing, Faculty of Nursing, Assiut University, Egypt. \\ 3. Lecturer of Family \&Community Health Nursing, Faculty of Nursing, Assiut University, Egypt.
}

\begin{abstract}
Background: Workers in sugar mills are exposed to occupational hazards as accidents, bagassosis and hearing loss in many manufacture parts of the sugar production. The aim of the study: to assess knowledge of workers regarding their occupational hazards at Sugarcane Factory Methods: Cross sectional research design was used in this study. It conducted at Sugarcane Factory. The total number of the studied sample was 541 workers; Simple random sample was used. Tools of the study: self-administrated questionnaire was used which included personal data, questions to determine their occupational hazards and knowledge of workers regarding occupational hazards Results: The mean age of workers was $45.74 \pm 8.44,62.1 \%$ of them had secondary education and $76.7 \%$ of them had $>10$ years of experience. According to their occupational hazard, $68.2 \%$ of workers had back pain, $63.2 \%$ complained from nervousness. According to their knowledge about occupational hazards, $71.2 \%$ of workers had poor knowledge. Also, there is statistically significant relationship between knowledge and their educational level $(\mathrm{P}$ value $=0.037)$. Conclusion: Almost of workers had poor of knowledge about occupational hazards also; the occupational hazards were prevalent among them. Recommendations: Training and health education programs should be implemented to increase workers' knowledge about occupational health hazard in sugarcane factory.
\end{abstract}

\section{Keywords: Sugarcane, Occupational Hazard \& Workers.}

\section{Introduction}

Sugar is one of the mainstays of person's nutrition. The five highest sugar manufacturing nations in the world are India, Brazil, Thailand, Australia and China. Consequently, $70 \%$ of the sugar is produced from sugarcane and 30\% from sugar beet and cassava (Nakhla\& El Haggar, 2014). Sugarcane agriculture in Egypt is greatly focused nearby the sugar factories in Upper Egypt. These focuses constitute $77 \%$ of the cane area in the country. Middle Egypt contains an extra $15 \%$ of the sugarcane region, after that the delta at $8 \%$ (Omar, 2019).

Sugar management process went through numerous stages including extraction, purification, evaporation, crystallization, centrifuge, drying and finishing. The incompetent process of sugar production indicates a break-down of substantial mechanisms and energy that come out and affects the environment and workers (Gunawan et al., 2018 \& Vu et al., 2020). An occupational hazard is typically a condition that has possibility to harm workers. There are two kinds of occupational hazards i.e. health hazards and safety hazard. Frequent and long term exposure to bagasse dust in sugarcane factory can lead to a group of severe respiratory problems such as bagassosis which may have permanent effects, even after exposure stops. Sugarcane workers have an increased threat of lung cancer; this may have a relation to the practice of burning foliage at the time of cane-cutting. The second most mentioned risk, related to long periods in a seated position was the back harms (Le Blond et al., 2017, Fatima \& Shahid, 2017).

Workers may be exposed to physical, chemical, and biological hazards that may lead to occupational disease which resulted from several activities involved in sugar production. Hearing loss is one of the most important consequences of noise exposure. Occupational hearing loss may be caused from noise in the factory while great temperatures from boilers and evaporators are likely lead to serious burns and high levels of dehydration. Other hazards include electric shocks, falls from high buildings, burns from steam used to operate turbines, burgess's fires in the dry season and gases from the lagoons which can cause skin diseases (Omusulah, 2013, Shahid et al., 2014, Biswas et al., 2016).

Occupational accidents are a continuous problem for Sugarcane workers also; they are exposed to the high toxicity of pesticides. They may also have an increased hazard of lung cancer, perhaps mesothelioma. Bagassosis is also a disease specific to the manufacturing as it may follow exposure to bagasse. The workers may also be influenced by 
chronic infections which decrease their productivity. The thermal exposure causes severe illnesses in addition to milder disorders such as heat rash, heat cramps, heat exhaustion, and heat syncope (Bener et al., 2012, Abdelwahab et al., 2019, Yazdanirad et al., 2020).

The World Health Organization (WHO) defined work-related diseases as multifactorial diseases in which the work environment and the performance of work contribute significantly to the causation of the disease. The occupational health problems in various processing units of the sugar industry are enormous, high concentration of dust in cane yard, bagasse dust in a mill and bagasse baling section are the primary reasons of respiratory problems amongst labors (Nayakavadi, 2014, Nambiema et al., 2020).

The deficiency of safety audits, labor inspections, personal protective equipment, and job rotation practice also, lack of ventilation systems, job dissatisfaction and deficiency of skills in ergonomics, communication and resources were the major associated factors caused by poor working conditions and lead to increasing in health and safety problems in sugarcane factory (Bonsa et al., 2018).

Occupational health has a strong focus on primary prevention of hazards. One of the important fields of interest of industry especially in developing countries is improving employee productivity and occupational health and safety. According to WHO, there are several risk factors at place of work that can lead not only to accidents but also to several health problems such as cancer, musculoskeletal problems, hearing impairment, stress related illnesses, circulatory, respiratory and several communicable illnesses. Occupational health precaution can help in avoiding these and has a positive economic impact on both national and institution level, and thus may be considered as a productive factor, rather than an economic burden (Kaynak et al., 2016, Gupta \& Kaur, 2019).

Occupational health nurse can participate in educating industrial workers considered occupational health hazards and help the industrial workers by providing education regarding occupational hazards and their preventive measures. Also, occupational health nurse have a combined knowledge of health and business that blends health skills to balance the requirement of a safe and healthy work environment with a "healthy" bottom line" (Bisht et al., 2016, Torre et al., 2020).

Occupational health nurse plays a chief role in helping to protect and improved the health of workers. The main focusing of the occupational health nurse is on keeping employees healthy, avoiding diseases and accidents and ensuring safe industrialized surroundings. Also, occupational health nurse is in a model situation to provide direction, counseling, training, and education for employers who want to improve their health (Ibrahim., 2017).

\section{Significant of the study}

Occupational health hazards have a harmless effect on the individual's health and safety as well as physical effectiveness. According to study conducting in Uganda, $90 \%$ of the workers affected by a physical hazard, $29.9 \%$ chemical hazards, $8.2 \%$ mechanical hazards, while $2.1 \%$ psychosocial hazards and $11.3 \%$ ergonomics hazard (Nafuna, 2019) Sugarcane workers have a high level of occupational accidents and are exposed to the high toxicity of pesticides. They may also have an enlarged hazard of lung cancer (Tamizharasan\& Mangalagowri, 2016). Knowledge about occupational health hazards and awareness of workers can reduction their exposure to different hazards which locate in place of work (Patil et al., 2016).

Aims of the study

1- To determine the occupational health hazards among sugarcane workers.

2- To assess sugarcane workers' knowledge regarding occupational health hazards in sugarcane factory.

Research questions

1- What is the kind of occupational health hazard in sugarcane factory?

2- Is sugarcane workers' had knowledge about occupational health hazard in their work?

\section{Research design}

Cross sectional research design was used in this study.

\section{Setting of the study}

The study was carried out at sugarcane factory in Armant, Luxor Governorate. The factory products white sugar, animal feed, molasses, bagasse (sucker) and filter slush. The work in the factory classified to three shifts. It consists of eight departments namely; (unloading, squeezers, steam boilers, turbines, cooking furnace, filling sugar, mechanical workshop and sulfur furnace) which included in the study. This factory was chosen because sugarcane workers have an increased exposure to occupational health problems and hazards as lung cancer.

\section{Sampling size and technique}

Total number of workers in sugarcane factory was 1393 which include engineers, chemists, technicians, electricians, workers and metal welders. Sample size was calculated with software Epi/Info version 7 with $99 \%$ confidence level and power $80 \%$ of the test. It was found to be 451 workers which increased to 541 to safeguard against non-response and drop out.

The sample size was distributed proportionate according to the number of workers in every 
department who classified as 46 from unloading section, 47 from milling section, 54 from boiler section, 103 from evaporation plant, 57 from vacuum plant, 18 from sulfur station, 38 from sugar packing, 149 from maintenance and 29 from power turbine.

Simple random sample was used. The researcher takes all workers who had the inclusion criteria and presented in the morning shift. The researcher prepared initially a list of all workers and then each worker is marked with a specific number. a random number selected from the list as number 1 then 3,5 , $7, \ldots .$. etc.

\section{Inclusion criteria}

Workers who had more than one year of experience and agreed to participate in the study were included.

Tools of the study

After reviewing related literature, self-administrated questionnaire was developed by the researcher to collect information from the Sugarcane workers, it was included:

Part 1: Consisted of five questions related demographic data such as age, educational level, marital status, working experience, job/ working section categories.

Part 2: Involved seven questions related to sugarcane workers' occupational health hazards such as work environment, chemical, psychological, biological, noise, heating and bagasse hazards.

Part 3: Contained twenty one questions related to knowledge of sugarcane workers regarding occupational health hazards such as occupational safety and health, occupational health programs, work environment, chemical, psychological, biological, noise, heating, bagasse hazards and causes of accidents. Skin, respiratory, musculoskeletal, vision and Hearing problems .......etc

\section{Scoring of knowledge}

The total grade of knowledge equal (80); a score of one was given for correct answer and zero was given for an incorrect answer and i don't know. If scores $<50 \%$ means poor knowledge, $50-60 \%$ for fair knowledge and more than $60 \%$ used for good knowledge.

\section{Validity of tools}

The content validity of the data collection tool was examined by three experts in Nursing Science in Assiut University. The tool was examined for content coverage, clarity, relevance, applicability, wording.

\section{Reliability of tools:}

Reliability was applied by the researchers for testing the internal consistency of the tool. Alpha reliability was 0.844

II- Data collection was carried out in three phases Preparatory phase: It included reviewing of current literature in the various aspects of the review using text books, articles, different studies, internet and journals in order to develop the study questionnaire for data collection.

\section{Administrative phase}

An official approval letter was obtained from the Dean of the Faculty of Nursing, Assiut University, to the director of the sugarcane plant in Armant, Luxor Governorate, and then sent to the Central Agency for Public Mobilization and Statistics, then to the Central Security Department. The approval letter was sent to the director of the sugarcane plant in Armant, and the director of the factory addressed the chairman and managing director of the Egyptian Sugar and Integrated Industries Company. The letter included permission to conduct the study.

Pilot study

Pilot study was being carried out before starting of data collection on 50 workers who included in the study. The aim of this study was to test the clarity of the tools and estimate the required time to fill the questionnaire.

\section{Data collection phase (Field work)}

Data were collected from workers in the sugarcane factory who included engineers, chemists, technicians, electricians and metal welders.Verbal informed consent was obtained from all the workers before the study enrollments, after that a detailed explanation on study objectives was done.

The questionnaire was self-administered at their workplace in the factory after full explanation of each item. It was distributed to be answered then collected. Data collection started from November, 2019 to January, 2020, two days a week and approximately from 22- 23 questionnaires were collected daily. An appropriate place for the interview has been prepared to ensure privacy and explain the questionnaire to the worker.

\section{Ethical considerations}

Research proposal was being approved from Ethical Committee in the Faculty of Nursing, Assiut University. There is no hazard for studied workers during application of the research. Oral consent was being obtained from workers that are willing to join in the study. Confidentiality and anonymity was being assured. Workers have the right to refuse to participate or withdraw from the study without any rationale at any time.

\section{Statistical Analysis}

- Data entry and data analysis were done using SPSS version 22 (Statistical Package for Social Science) and Excel 2016 program. Data were presented as number, percentage, mean, and standard deviation.

- Chi-square test was used to compare between qualitative variables. P-value considered statistically significant when $\mathrm{P}<0.05$. 


\section{Results}

Table (1): Distribution of studied workers according to their personal data at Sugarcane Factory in Luxor Governorate.

\begin{tabular}{|c|c|c|}
\hline Items & No. $(541)$ & $\%$ \\
\hline \multicolumn{3}{|l|}{ Age group : (years) } \\
\hline$<35$ & 57 & 10.5 \\
\hline $35-44$ & 156 & 28.8 \\
\hline$\geq 45$ & 328 & 60.6 \\
\hline Mean \pm SD (Range) & \multicolumn{2}{|c|}{$45.74 \pm 8.44(25.0-59.0)$} \\
\hline \multicolumn{3}{|l|}{ Educational level: } \\
\hline Do not read or write & 15 & 2.8 \\
\hline Read and write & 79 & 14.6 \\
\hline Primary & 8 & 1.5 \\
\hline Preparatory & 21 & 3.9 \\
\hline Secondary & 336 & 62.1 \\
\hline University & 76 & 14.0 \\
\hline Postgraduate & 6 & 1.1 \\
\hline \multicolumn{3}{|l|}{ Marital status: } \\
\hline Single & 30 & 5.5 \\
\hline Married & 496 & 91.7 \\
\hline Divorced & 12 & 2.2 \\
\hline Widowed & 3 & 0.6 \\
\hline \multicolumn{3}{|l|}{ Working experience: (years) } \\
\hline$<6$ & 21 & 3.9 \\
\hline $6-10$ & 105 & 19.4 \\
\hline$>10$ & 415 & 76.7 \\
\hline \multicolumn{3}{|c|}{ Job/ working section categories: } \\
\hline Unloading section & 46 & 8.5 \\
\hline Milling section & 47 & 8.7 \\
\hline Boiler section & 54 & 10.0 \\
\hline Evaporation plant & 103 & 19.0 \\
\hline Vacuum plant & 57 & 10.5 \\
\hline Sulfur station & 18 & 3.3 \\
\hline Sugar packing & 38 & 7.0 \\
\hline Maintenance & 149 & 27.5 \\
\hline Power turbine & 29 & 5.4 \\
\hline
\end{tabular}




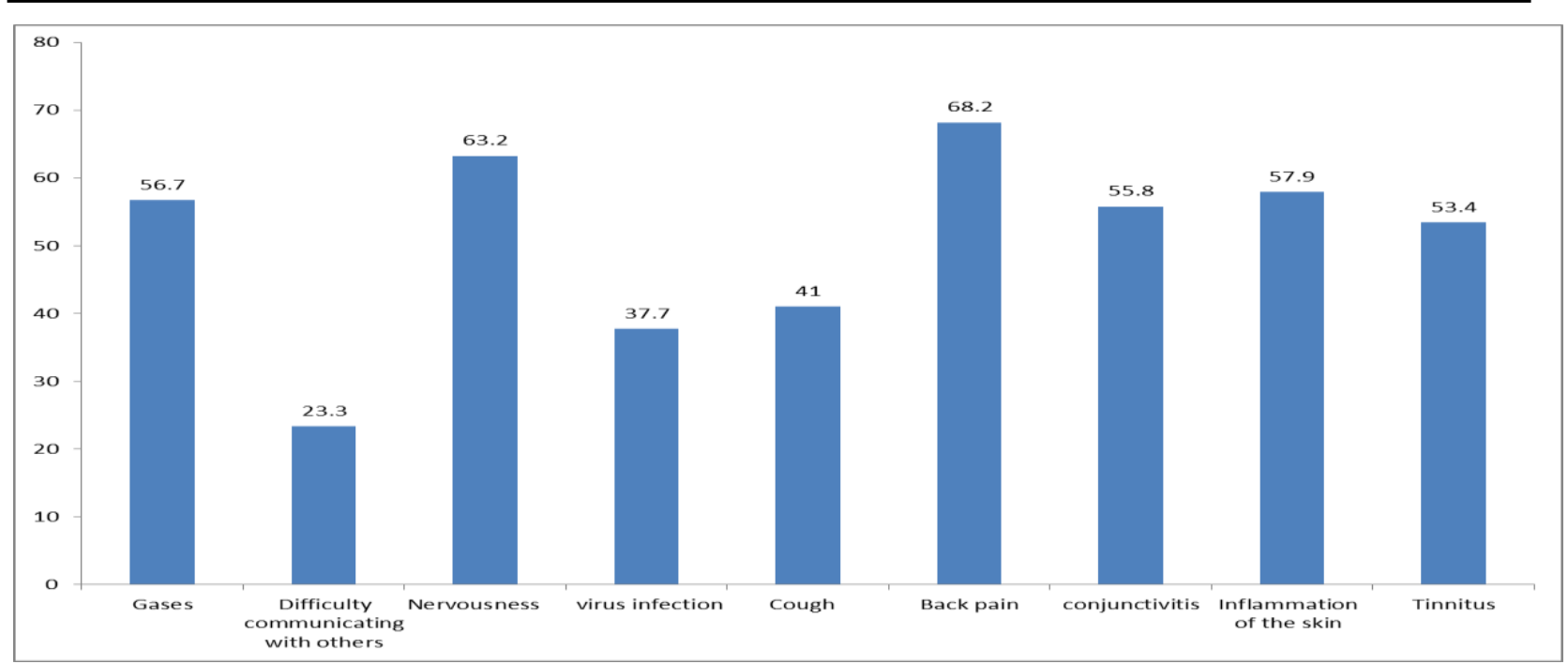

Figure (1): Distribution of studied workers according to their occupational hazard and problems at Sugar Cane Factory in Luxor Governorate

Table (2): Distribution of studied workers according to their Knowledge level about occupational hazards at Sugarcane Factory in Luxor Governorate

\begin{tabular}{|l|c|c|}
\hline \multicolumn{1}{|c|}{ Knowledge level } & No. (541) & \% \\
\hline Poor & 385 & 71.2 \\
\hline Fair & 112 & 20.7 \\
\hline Good & 44 & 8.1 \\
\hline
\end{tabular}

Table (3): Relation between personal data and knowledge level regarding occupational hazards at Sugarcane Factory in Luxor Governorate

\begin{tabular}{|c|c|c|c|c|c|c|c|}
\hline & \multicolumn{6}{|c|}{ Knowledge level } & \multirow{3}{*}{ P-value } \\
\hline & \multicolumn{2}{|c|}{$\begin{array}{c}\text { Poor } \\
(n=385)\end{array}$} & \multicolumn{2}{|c|}{$\begin{array}{c}\text { Fair } \\
(n=112)\end{array}$} & \multicolumn{2}{|c|}{$\begin{array}{c}\text { Good } \\
(n=44)\end{array}$} & \\
\hline & No. & $\%$ & No. & $\%$ & No. & $\%$ & \\
\hline \multicolumn{7}{|l|}{ Age: (years) } & \multirow{4}{*}{0.296} \\
\hline$<35$ & 43 & 75.4 & 9 & 15.8 & 5 & 8.8 & \\
\hline $35-44$ & 104 & 66.7 & 34 & 21.8 & 18 & 11.5 & \\
\hline$\geq 45$ & 238 & 72.6 & 69 & 21.0 & 21 & 6.4 & \\
\hline \multicolumn{7}{|l|}{ Educational level: } & \multirow{3}{*}{ 0.037* } \\
\hline Less than secondary & 97 & 78.9 & 22 & 17.9 & 4 & 3.3 & \\
\hline Secondary/ high education & 288 & 68.9 & 90 & 21.5 & 40 & 9.6 & \\
\hline \multicolumn{7}{|l|}{ Working experience: (years) } & \multirow{3}{*}{0.277} \\
\hline$\leq 10$ & 94 & 74.6 & 26 & 20.6 & 6 & 4.8 & \\
\hline$>10$ & 291 & 70.1 & 86 & 20.7 & 38 & 9.2 & \\
\hline
\end{tabular}

*Statistically Significant Difference at P. value $<0.05$

Table (1): Shows the distribution of studied workers according to their personal data at sugarcane factory in Luxor Governorate. It revealed that, $60.6 \%$ of workers aged $\geq 45$ years mean $\pm \mathrm{SD} 45.74 \pm 8.44$, $62.1 \%$ of them had secondary education and $91.7 \%$ of them had married. Regard to years of work experience, $76.7 \%$ of them had $>10$ years of experience. Concern to job/ working section categories, $27.5 \%$ of them was in maintenance.

Figure (1): Cleared the distribution of studied workers according to their occupational hazard and problems at sugarcane factory in Luxor Governorate. It showed that, $68.2 \%$ of workers had back pain, $63.2 \%$ complained from nervousness, $57.9 \%$ suffered from inflammation of the skin, $56.7 \%$ of them had 
gases, $55.8 \%, 53.4 \%$ had conjunctivitis and tinnitus respectively.

Table (2): Show the distribution of studied workers according to their knowledge level at sugarcane factory in Luxor Governorate. It revealed that, $71.2 \%$ of workers had poor knowledge, $20.7 \%$ of them had fair knowledge and $8.1 \%$ of them had good knowledge.

Table (3): Show the Relation between personal data and knowledge level regarding occupational hazards at sugarcane factory in Luxor Governorate. It revealed that there is statistically significant relationship between level of knowledge and their educational level $(\mathrm{P}$ value $=0.037)$. while there are no statistically significant relationship between level of knowledge, age and working experience $(\mathrm{P}$ value $=$ $0.296 \& 0.277)$ respectively.

\section{Discussion}

Workers may be exposed to physical, chemical, and biological hazards at workplace which caused occupational diseases. The accidents of workers in sugarcane factory are due to lack of safety measures, no consonantal training and education program, safety protections were not provided to the vibrating mechanisms (Abdelwahab, 2019).

In referral to personal characteristics of workers, the mean age of the workers was $45.74 \pm 8.44$ (25.0-59.0) years. The present study in the same line with (Abdelwahab et al., 2019) who study knowledge and practice of workers regarding occupational health hazards in abou-qurkas sugar factory, EL-Minia governorate, Egypt and report that mean age of studied sample was $44.7 \pm 8.7$ years.

The results of the present study were in contrast with (Vasave \& Anap., 2016) who study prevalence of musculoskeletal disorders among sugarcane workers and reported that, the mean age of the workers was 39 +8.34 (19.0-64.0) years and also with (Yartire et al., 2014) who conducted a study under title complete survey of biston sugar production factory's occupational hearing and report that mean age was $35.8 \pm 8.7$ years.

As regard to the education level, about three fifths of workers were secondary level education. These findings were also supported by the results of (Abdelwahab et al., 2019) who reported that, about three fifths of them were secondary level education.

The current results opposed with (Vasave \& Anap., 2016) who reported that, about two fifths of workers were educated up to diploma/Degree and with a study conducted in Ethiopia (Debela et al., 2019) who reported that, about two fifths of workers were education level Primary.
Regarding to the marital status, the majority of the studied workers were married. This result agree with (Bonsa et al., 2018, Taffere et al., 2019 \& Debela et al., 2019) who reported that the majority of the studied workers were married.

Concerning to the working experience, about three quarters of them were $>11$ years. This result disagreed with Bonsa et al., (2018) who found that more than two fifths of them were $\geq 11$ years, also it differed with Panakobkit et al., (2019) who found that more than one sixth of them were $\geq 10$ years and with Debela et al., (2019) who found that about two fifths of them were $\geq 11$ years.

As regard to the job/ working section categories, about nine hundred percent of workers in milling section, ten hundred percent in boiler section, less than one fifth in evaporation plant, about ten hundred percent in vacuum plant, about three hundred percent in sulfur station, seven hundred percent in sugar packing, about one quarter in maintenance and about five hundred percent in power turbine.

The current results were similar to Bonsa et al., (2018) who found that seven hundred percent in milling section, less than one fifth in boiler section, less than one fifth in evaporation plant, about seven hundred percent in vacuum plant, about two hundred percent in sulfur station, about five hundred percent in sugar packing except the maintenance were nine hundred percent and less than one fifth in power turbine.

As regard to the workers exposure to occupational health hazard at sugarcane factory, more than half of them had chemical hazard (gases), about three fifths of them had psychological hazard (nervousness) and less than two fifths of them had biological hazard (virus). This result contradicted with Nafuna, (2019) who study occupational safety and health hazard in work places, a case study of Sugar Corporation of Uganda Limited and stated and found that four hundred percent of them had psychological hazard and four hundred percent of them had biological hazard except the chemical hazard report more than half.

Relating to the workers exposure to occupational health problems at sugarcane factory, about two fifths of them suffering from respiratory problems (cough), more than three fifths of them had musculoskeletal problems (back pain), about half of them had vision problems (conjunctivitis), less than three fifths of them had skin problems (inflammation of the skin), about half of them had hearing problems (tinnitus).

The study results were not in congruence with Bisht et al., (2016) who reported that, six hundred percent of employees were suffering from respiratory problems (cough with sputum), about two fifths of them had musculoskeletal problems (back, joint or 
muscle problems), more than one quarter of them had Vision problems (burning in eyes, stinging or tearing eyes), eight hundred percent of them had skin problems (skin infection) and about one sixth of them had hearing problems. Also, it opposed with Fatima \& Shahid, (2017) who study occupational health and safety conditions of a sugar mill in Pakistan and reported that ten hundred percent of them had hearing problems.

In addition the present study contracted with a study conducted in Iran Zare et al., (2017) who found that about one sixth of workers were suffering from various degrees of hearing loss and with Somasundaram \& Bangal, (2012) who found that about one sixth of workers were suffering from diseases of respiratory system, about one eighth of them had complained about backache and joint pains and nine hundred percent were suffering from common skin diseases like fungal infections, scabies, eczema. Also it contracted with Abdelwahab et al., (2019) who reported that nearly three quarters of workers had difficulty breathing and about one sixth of them had cough.

These findings were also consistent with the results of Vasave \& Anap, (2016) who study the prevalence of musculoskeletal disorders among sugarcane workers and reported that half of workers had lower back pain, more than two fifths of them had cough, one eighth of them had conductive deafness and noise induced hearing loss. Also, pulmonary impairment was found in about nine hundred percent of the workers and Six out of ten hundred percent had allergic conjunctivitis. The current results were similar to Gascon et al., (2012) who stated that about three quarters of workers had eye problems and less than one fifth of them had shortness of breathing and with Pawar \& Shinde., (2019) who reported that, about three fifths of workers were suffering from various impairments in pulmonary function test.

Concerning with knowledge level of workers regarding occupational hazards, about three quarters of them had poor knowledge, about one fifth of them had fair knowledge and eight hundred percent of them had good knowledge. The results of this study contrasted with Abdelwahab et al., (2019) who reported that all workers of the study sample had poor knowledge about occupational health hazards.

The current results in contrast with Patil et al., (2016) who conducted a study to assess knowledge on occupational health hazards among the workers of Jaggery factory with special emphasis to prepare health educational material in selected Jaggery factories at Kolhapur, India who stated that, eight hundred percent of workers had poor knowledge, about three quarters of them had average knowledge and less than one fifth of them had good knowledge.
In my opinion the difference in these results may be due to the difference of sample size, culture and level of education in all studies.

\section{Conclusion \& Recommendation}

Almost of workers had poor of knowledge regarding occupational health hazards. The most common health hazards and problems among workers were difficulty communicating with others as a hazard of noise, Nervousness, back pain, conjunctivitis, inflammation of the skin and tinnitus. There was statistically significant difference between knowledge about occupational health hazards and educational level.

The study recommended the following

1- Training and health education programs should be provided for workers to increase their knowledge about occupational health hazard.

2- Frequently checkup of health status for workers for premature finding of occupational hazards to screen their health status and primary case finding.

3- The recognized factors should be considered for suitable occupational health and safety applicability to protection the health of all workers.

4- Additional researches should be taken place to discover the health hazards in the sugarcane factory.

\section{Acknowledgments}

The researchers would like to thank all participated workers in the sugarcane factory.

Funding: None

Competing interests: None declared.

\section{Reference}

1. Abdelwahab, A., Bader EL-Din, S., \& Mohammed, A., (2019): Effect of Health Education Program on Knowledge and Practice of Workers Regarding Occupational Health Hazards at Sugar Factory. Minia Scientific Nursing Journal (Print) (ISSN 2537-012X) Vol.(4), No.(1).

2. Abdelwahab, A., Bader EL-Din, S., \& Mohammed, A., (2019): Knowledge and Practice of Workers Regarding Occupational Health Hazards At Sugar Factory, IOSR Journal of Nursing and Health Science (IOSR-JNHS) eISSN: 2320-1959.p- ISSN: 2320-1940 Vol.(8), No.(2), Pp. 40-48.

3. Bener, A., Abdul Rahman, Y., Abdel Aleem, E., \& Khalid, M., (2012): Trends and characteristics of injuries in the State of Qatar: Hospital-based study. International Journal of Injury Control and Safety Promotion, Vol. (19), No. (4), Pp. 368-372. doi:10.1080/17457300.2012.656314

4. Bisht, R., Rawat, M., Singh, N., Bisht, N., Rawat, P., Thapliyal, P., \& Abhishek Gideon, 
M., (2016): A Descriptive Study on Prevalence of Occupational Health Hazards among Employees of Selected Sugarcane Factory in Dehradun, Uttarakhand. IOSR Journal of Nursing and Health Science, Vol.(05), No.(04), Pp. 01-05. doi:10.9790/1959-0504020105.

5. Biswas, G., Bhattacharya, A., \& Bhattacharya, R., (2016): A review on the occupational health of sugar cane workers Gourab International Journal of Biomedical Research; Vol.(7), No.(8), Pp. 568570.

6. Bonsa, M., Taffere, G., \& Alemayehu, M., (2018): Magnitude of occupational exposure to bagasse dust and associated factors among Metehara sugarcane factory workers, east Shoa, Ethiopia. Journal of Public Health, Vol.(27), No.(2), Pp. 203-210. doi:10.1007/s10389-0180939-z

7. Debela, M., Taferi, G., \& Assefa, M., (2019): Occupational Exposure to Hand-arm Vibration and Associated Factors among Metehara Sugar Industry Workers: East-shoa, Ethiopia, Journal of Environmental Hazards Vol.(2), No.(1)

8. Fatima, S., \& Shahid, I., (2017): Study of occupational health and safety conditions of a sugar mill in Pakistan, Journal of Biodiversity and Environmental Sciences (JBES). Vol.(11), No.(1), Pp. 97-104.

9. Gascon, M., Kromhout, H., Heederik, D., Eduard, W., \& Van, B., (2012): Respiratory, allergy and eye problems in bagasse-exposed sugar cane workers in Costa Rica. Occupational and Environmental Medicine, Vol.(69), No.(5), Pp. 331-338. doi:10.1136/oemed-2011-100029

10. Gunawan, Bantacut, T., Romli, M., \& Noor, E., (2018): Production and productivity improvement through efficiency sugar mill. International Journal of Advanced Research, Vol.(6), No.(2), Pp. 1931-1941. doi:10.21474/ijar01/6638

11.Gupta, A., \& Kaur, H., (2019): Occupational Health Problems of Phulkari Artisans. International Journal of Research in Social Sciences, Vol.(9), No.(7), Pp. 697-710.

12. Ibrahim, A., (2017): Effect of an educational program about occupational health and safety on knowledge, attitude, and practice of workers in textile factory in Damietta city. IOSR Journal of Nursing and Health Science, Vol.(6), No.(2), Pp. 66-78. doi:10.9790/1959-0602016678

13.Kaynak, R., Tuygun, A., Elci, M., \& Tamer, I., (2016): Effects of occupational health and safety practices on organizational commitment, work alienation, and job performance: Using the PLSSEM approach. International Journal of Business and Management, Vol.(11), No.(5), Pp. 146. doi:10.5539/ijbm.v11n5p146
14.Le Blond, J., Woskie, S., Horwell, C., \& Williamson, B., (2017): Particulate matter produced during commercial sugarcane harvesting and processing: A respiratory health hazard? Atmospheric Environment journal, vol.(149), Pp. 34-46. http://dx.doi.org/10.1016/j.atmosenv.2016.11.012

15. Nafuna, A., (2019): Occupational Safety and Health Hazards in Work Places, Case Study of Sugar Corporation of Uganda Limited, Master Thesis to the School of Foretry, Environmental and Geographical Sciences, Makerere University.

16. Nakhla, D., \& El Haggar, S., (2014): Environmentally Balanced Sugarcane Industry In Egypt, International Journal of Agricultural Policy and Research Vol.(2), No.(9), Pp. 321-328.

17. Nambiema, A., Bertrais, S., Bodin, J., Fouquet, N., Aublet-Cuvelier, A., Evanoff, B., \& Roquelaure, Y., (2020): Proportion of upper extremity musculoskeletal disorders attributable to personal and occupational factors: Results from the French Pays de la Loire study. BMC Public Health, Vol.(20 ), No.(1), doi:10.1186/s12889020-08548-1

18. Nayakavadi, S., (2014): Assessment of respiratory stress in work place environment of sugar industry. Indian Journal of Applied research; Vol.(7), No.(4), Pp. 535-36.

19. Omar, R., (2019): Increasing Sugar Supply on Expanded Beet Production. Report about Egypt Sugar Annual, USDA.

20. Omusulah, I., (2013): Perceived influence of occupational health and safety practices on job satisfaction among employees in Chemelil sugar company limited, Kenya, puplished thesis Pp. 149.

21.Panakobkit, W., Sakunkoo, P., \& Chamroen, P., (2019): Health belief model and behavioural usage of respiratory protective equipment among sugarcane workers in Northeast of Thailand: A cross-sectional analytical study. Journal of Clinical and Diagnostic Research, Vol.(13), No.(12), doi:10.7860/jcdr/2019/42085.13380

22.Patil, S., Salunkhe, A., Kakade, N., Katti, A., \& Mohite, V., (2016): A Study to assess knowledge on occupational health hazards among the workers of Jaggery factory with special emphasis to prepare health educational material in selected Jaggery factories at Kolhapur, India, international journal of innovative research \& development; Vol.(5), No.(6), Pp. 124-132.

23.Pawar, P., \& Shinde, S., (2019): Prevalence of impairment in pulmonary function test in sugar distillery industry workers in karad taluka. Asian Journal of Pharmaceutical and Clinical Research, 
Vol.(12), $\quad$ No.(2), $\quad$ Pp. 428-431. doi:10.22159/ajpcr.2019.v12i2.30093

24.Shahid, M., Kousar, N., \& Ajaz, M., (2014): Impact of Industrial Noise Pollution on Human Health, International Journal of Core Engineering \& Management (IJCEM). (ISSN: 2348-9510) Vol.(1), No.(6).

25.Somasundaram, K., \& Bangal, V., (2012): Living and health conditions of migratory sugarcane harvest workers of ahemdngar district in Maharashtra. International Journal of Biomedical and Advance Research, Vol.(3), No.(2), doi:10.7439/ijbar.v3i2.287

26. Taffere, G., Bonsa, M., \& Assefa, M., (2019): Magnitude of occupational exposure to noise, heat and associated factors among sugarcane factory workers in Ethiopia, 2017. Journal of Public Health. doi:10.1007/s10389-019-01070-8

27. Tamizharasan, M., \& Mangalagowri, P., (2016): Assess the Level of Knowledge on Prevention and Control of Bagassosis among Workers in Sugarcane Industry, International Journal of Science and Research (IJSR), Vol.(5), No.( 9), Pp. 1813-1814.

28. Torre, G., Andreano, F., Lecce, G., Muzio, M., Chiarini, M., \& Pulimeno, M., (2020): The Occupational Health Nurse and his/her role in the prevention of work-related diseases: results of an observational study. Annali di Igiene, Medicina Preventiva e di Comunità; Vol.(32), No.(1), Pp. 315. doi:10.7416/ai.2020.2325

29. Vasave, S., \& Anap, D., (2016): Prevalence of musculoskeletal disorders among sugarcane workers - A cross sectional study, Indian Journal of Basic and Applied Medical Research; Vol.(5), No.(2), Pp. 756-762.

30.Vu, T., LeBlanc, J., \& Chou, C., (2020): Clarification of sugarcane juice by ultrafiltration membrane: Toward the direct production of refined cane sugar. Journal of Food Engineering, Vol.(264 ). doi:10.1016/j.jfoodeng.2019.07.029

31. Yartire, H., Weisi, B., \& Hashemian, A., (2014): Complete Survey of Biston Sugar Production Factory's Occupational Hearing, Advances in Biological Research; Vol.(8), No.(5), Pp. 187-190. doi: 10.5829/idosi.abr.2014.8.5.84294

32. Yazdanirad, S., Golbabaei, F., Monazzam, M., Dehghan, H., \& Foroushani, A., (2020): Development of a personal heat strain risk assessment (PHSRA) index in workplaces and its validation. Biomedcentral (BMC) Public Health, Vol.( 20), No.(1), doi:10.1186/s12889-020-088744
33.Zare, S., Monazzam, M., Behzadi, M., Hasanvand, D., \& Ahmadi, S., (2017): Hearing loss among Fasa sugar factory workers', Fars Provincre, Iran. Journal of Occupational Health and Epidemiology, Vol.(6), No.(2), Pp. 70-76. doi:10.29252/johe.6.2.70 